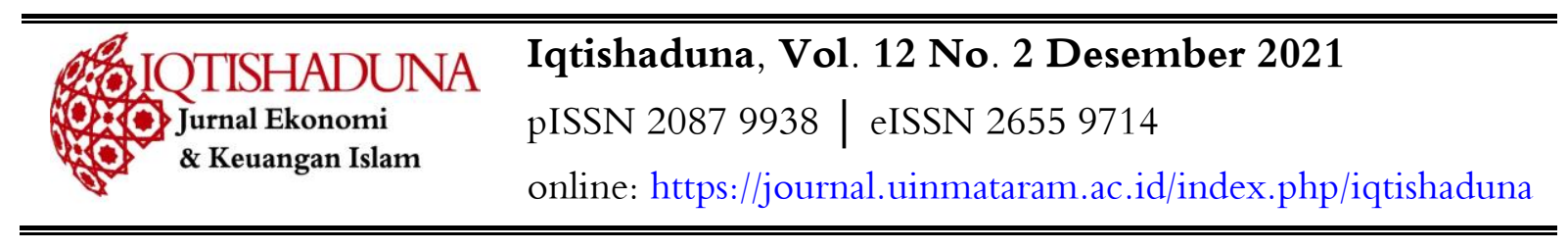

\title{
LITERASI KEUANGAN SYARIAH DAN KEPUTUSAN INVESTASI: ANALISIS SOSIAL DEMOGRAFI
}

\author{
Elfira Maya Adiba \\ UHW Perbanas \\ merufira@gmail.com
}

\begin{abstract}
Islamic financial literacy is important because it has an influence on financial planning and investment decisions. This study aims to determine the Islamic financial literacy index of the people of Surabaya, the influence of socio-demographic factors on Islamic financial literacy, the influence of Islamic financial literacy on financial planning and investment decisions. The data analysis technique that used in this research is partial least square (PLS). The results of this study are demographic factors and education level have no effect on Islamic financial literacy. Sharia financial literacy also has no effect on financial planning. Another result is that Islamic financial literacy has a significant effect on investment decisions.
\end{abstract}

Keywords: Islamic financial literacy, Islamic financial planning, Investation decision

\section{PENDAHULUAN}

Indonesia merupakan negara dengan penduduk muslim terbesar di dunia. Besarnya jumlah penduduk muslim di Indonesia berpotensi menjadi nasabah industri keuangan syariah (Alamsyah, 2012). Total aset keuangan syariah di Indonesia hingga Agustus 2017 (tidak termasuk Saham Syariah) mencapai Rp 1.048,8 triliun. Aset keuangan syariah ini terdiri dari aset Perbankan Syariah Rp 389,74 triliun, IKNB Syariah Rp 99,15 triliun, dan Pasar Modal Syariah Rp 559,59 triliun. Jumlah tersebut jika dibandingkan dengan total aset industri keuangan yang mencapai Rp 13.092 triliun, maka market share industri keuangan syariah sudah mencapai 8,01\%. Berikut ini adalah tabel 1 yang menunjukkan market share keuangan syariah di Indonesia.

Tabel 1. Market Share Industri Keuangan Syariah Indonesia per Agustus 2017

\begin{tabular}{lccc}
\hline \multirow{1}{*}{ Industri } & \multicolumn{2}{c}{ Total Aset (dalam triliun rupiah) } & \multirow{2}{*}{ Market Share (\%) } \\
& \multicolumn{2}{c}{ Syariah } & \\
\cline { 2 - 3 } & Total (Konvensional + Syariah) & Syn & \\
Perbankan & $7.158,40$ & 389,74 & $5,44 \%$ \\
IKNB & $2,073.43$ & 99,15 & $4,78 \%$ \\
Pasar Modal & $3.861,09$ & 559,59 & $14,49 \%$ \\
TOTAL & $13,092.91$ & $1,048.48$ & $\mathbf{8 . 0 1} \%$ \\
\hline
\end{tabular}

Sumber: Otoritas Jasa Keuangan, 2017 
Elvira Maya Adiba. Literasi Keuangan Syariah, Keputusan Investasi, Sosial Demografi

Market share keuangan syariah di Indonesia per Agustus 2017 tersebut sudah menjapai 8,01\%. Angka tersebut meningkat dibandingkan market share keuangan syariah di Indonesia pada akhir tahun 2016 yang sebesar 5,3\% (Sholikah, 2017). Market share keuangan syariah memang sudah meningkat, namun angka tersebut masih kecil dibandingkan market share keuangan konvensional di Indonesia.

Pengetahuan tentang keuangan berhubungan dengan literasi keuangan. Otoritas Jasa Keuangan (OJK) mendefinisikan literasi keuangan merupakan sikap dan perilaku selain pengetahuan, keterampilan, dan keyakinan sebagai upaya peningkatan kualitas pengambilan keputusan dan pengelolaan keuangan individu. Indeks literasi keuangan masyarakat Indonesia pada tahun 2016 adalah 29,66\% dengan indeks inklusi keuangan 67,82\%. Indeks literasi keuangan syariah pada tahun 2016 adalah 8,11\% dengan indeks inklusi keuangan 11,06\% (Otoritas Jasa Keuangan, 2016). Rendahnya indeks keuangan syariah ini bisa dikaitkan dengan market share keuangan syariah secara nasional yang baru sekitar 8\%. Dalam rangka meningkatkan market share keuangan syariah di Indonesia maka masyarakat juga harus lebih melek terhadap keuangan syariah, sehingga inklusi atau keterikatan dengan produk keuangan syariah juga akan semakin meningkat.

Islam juga menjelaskan bahwa literasi atau pengetahuan adalah penting dikuasai sehingga seorang muslim dapat membedakan mana yang halal dan haram dalam Islam (Antara et al., 2016). Hal ini dijelaskan dalam Al-Qur'an surat Al-An'am ayat 119 yang artiny “Mengapa kamu tidak mau memakan (binatang-binatang yang halal) yang disebut nama Allab ketika menyembelihnya, padahal sesunggubnya Allab telah menjelaskan kepada kamu apa yang diharamkan-Nya atasmu, kecuali apa yang terpaksa kamu memakannya. Dan sesunggubnya kebanyakan (dari manusia) benar benar hendak menyesatkan (orang lain) dengan hawa nafsu mereka tanpa pengetabuan. Sesunggubnya Tuhanmu, Dialah yang lebih mengetahui orangorang yang melampaui batas".

Ayat tersebut menunjukkan bahwa tanpa pengetahuan tentang halal atau haram maka seseorang dapat salah atau misleading terhadap apa yang dikerjakannya (Antara et al., 2016). Hal ini juga berlaku pada tingkah laku bermuamalah, dimana sangatlah penting untuk memahami tentang keuangan yang sesuai dengan syariah, sehingga tidak salah dalam menempatkan dana atau berinvestasi, dimana Islam tidak memperbolehkan adanya riba.

Keuangan syariah membutuhkan pengukuran tingkat literasi keuangan yang berbeda dengan pengukuran tingkat literasi keuangan konvensional. Salah satu contohnya pada pengukuran literasi keuangan dasar yang mengukur pengetahuan tingkat suku bunga, efek inflasi, dan konsep diversifikasi risiko (Hidajat \& Hamdani, 2017). Sedangkan dalam pengukuran literasi keuangan syariah memasukkan pertanyaan tentang riba, gharar, serta aspek halal dan haram. 
Faktor sosial demografi berperan pada tingkat kemelekan atau literasi keuangan syariah. Penelitian yang dilakukan oleh Al-Hassan Al-Tamimi \& Anood Bin Kalli (2009) menunjukkan bahwa jenis kelamin dan tingkat pendidikan berpengaruh positif dan signifikan terhadap literasi keuangan para investor di Arab Saudi. Dosen di Indonesia yang bergelar doktor lebih melek terhadap pengetahuan keuangan syariah. Dosen yang berusia 36-50 tahun juga lebih melek terhadap keuangan syariah (Setyawati \& Suroso, 2016).

Seorang individu dapat dikatakan well literate jika memiliki pengetahuan dan keyakinan tentang lembaga, produk dan layanan jasa keuangan, serta keterampilan dalam mengetahui fitur, manfaat, risiko, hak dan kewajiban dari produk dan layanan jasa keuangan tersebut (Otoritas Jasa Keuangan, 2017). Literasi keuangan syariah juga berpengaruh terhadap perencanaan pengelolaan keuangan dan keputusan berinvestasi pada keuangan syariah. Seseorang dengan tingkat literasi keuangan yang tinggi maka akan semakin baik dalam perencanaan keuangannya (Setyowati et al., 2018). Seorang individu sebelum berinvestasi harus direncakan dengan matang sehingga bisa membuat keputusan yang rasional dan efektif.

Abdeldayem (2016) dalam penelitiannya menunjukkan ada perbedaan dalam pemilihan produk investasi pada kelompok dengan tingkat literasi tinggi dan rendah. Kelompok responden dengan tingkat literasi keuangan yang tinggi lebih memilih berinvestasi pada produk keuangan yang berisiko tinggi dengan pengembalian yang tinggi, sebaliknya kelompok responden dengan literasi keuangan yang rendah lebih memilih berinvestasi pada produk keuangan yang aman. Hal ini menunjukkan bahwa tingkat literasi keuangan memiliki pengaruh terhadap keputusan investasi.

Penelitian-penelitian tentang pengaruh sosial demografi terhadap literasi keuangan syariah serta pengaruh literasi keuangan terhadap perencanaan keuangan syariah dan keputusan investasi masih dilakukan secara parsial. Hal ini menjadi menarik untuk melakukan penelitian dengan menggabungkan keduanya, sehingga akan didapatkan hasil yang lebih komprehensif. Berikut adalah gambar kerangka konseptual dalam penelitian ini:

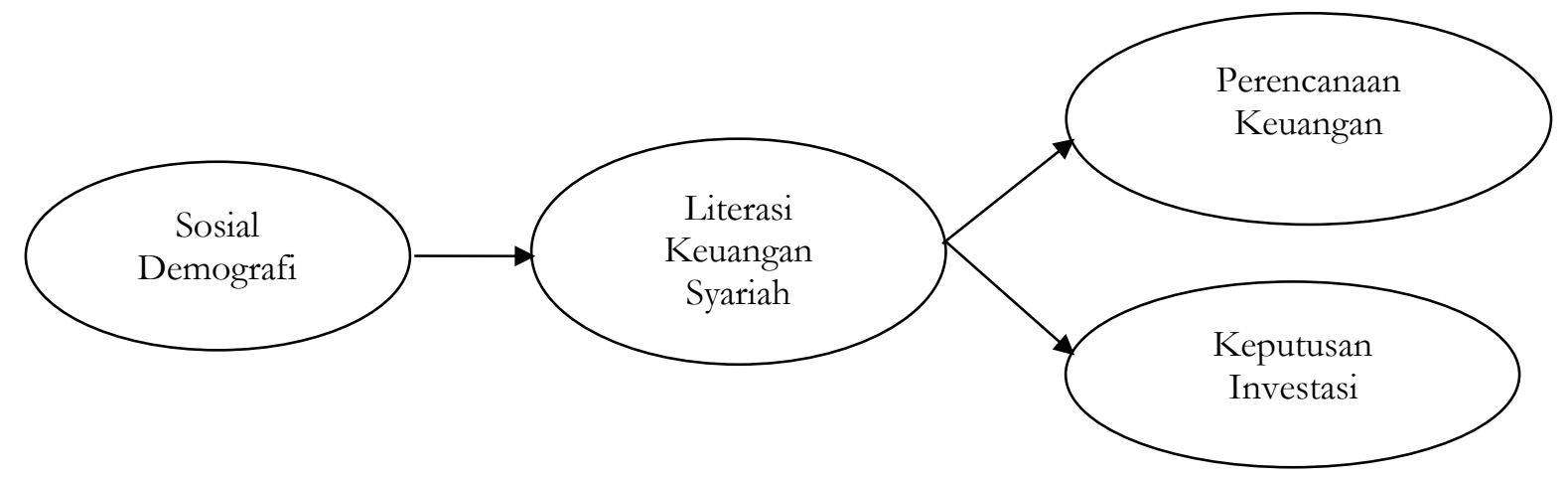

Gambar 1. Kerangka Konseptual 
Elvira Maya Adiba. Literasi Keuangan Syariah, Keputusan Investasi, Sosial Demografi

\section{METODOLOGI}

Penelitian ini menggunakan pendekatan kuantitatif. Jenis data dalam penelitian merupakan data primer dimana data didapat secara langsung dari responden. Sumber data dalam penelitian ini yaitu penyebaran kuesioner. Teknik sampel yang digunakan dalam penelitian ini adalah sampling purposive yang merupakan teknik penentuan sampel dengan pertimbangan tertentu (Anshori \& Iswati, 2009). Kriteria sampel dalam penelitian ini antara lain pendidikan minimal SMA dan mempunyai produk investasi pada keuangan syariah.

Jumlah responden dalam penelitian ini sebanyak 191 responden, dimana sebanyak 150 yang memenuhi syarat. Data penelitian yang sudah terkumpul, kemudian akan dianalisis menggunakan partial least square (PLS). Hair et al. (Hair, 2017) menjelaskan, PLS adalah metode statistika SEM berbasis varian (variance-based) yang secara simultan dapat melakukan pengujian model pengukuran sekaligus pengujian model struktural, dan didesain untuk menyelesaikan permasalahan SEM ketika terjadi hal-hal spesifik pada data, seperti ukuran sampel penelitian kecil, missing value, dan tidak memenuhi asumsi.

Variabel-variabel dalam penelitian ini yaitu jenis kelamin, pendidikan terakhir, literasi keuangan Syariah, perencanaan keuangan, dan keputusan investasi. Pada variabel jenis kelamin, peneliti menggunakan variabel dummy yaitu pria $=1$ dan wanita $=2$. Pada variabel tingkat pendidikan, tingkat pendidikan terakhir SMA/SMK/MA = 1, Diploma (D1/D2/D3) = 2, Sarjana $(\mathrm{S} 1)=3$, dan Pascasarjana $(\mathrm{S} 2 / \mathrm{S} 3)=4$.

Literasi keuangan syariah didefinisikan sebagai tingkat dimana masyarakat memiliki pengetahuan keuangan syariah dan keterampilan yang dapat mempengaruhi keputusan keuangannya. Literasi keuangan syariah diukur menggunakan indikator yang mengacu pada penelitian Hidajat dan Hamdani (Hidajat \& Hamdani, 2017). Perencanaan keuangan pribadi merupakan seperangkat perencanaan keuangan terkait pengelolaan uang, pembiayaan, perencanaan dana untuk pensiun, mortgage, dan investasi pada sektor keuangan syariah. Perencanaan keuangan diukur menggunakan indikator yang mengacu pada penelitian Boon et al. (2011). Keputusan Investasi didefinisikan sebagai pengambilan keputusan oleh masyarakat untuk investasi dalam keuangan syariah untuk mendapatkan pengembalian yang halal dan berkah. Penilain masing-masing indikator pada variabel perencanaan keuangan pribadi dan keputusan investasi menggunakan skala likert 1 -5. Skor 1 = sangat tidak setuju, $2=$ tidak setuju, $3=$ raguragu, $4=$ setuju, dan $5=$ sangat setuju. 


\section{HASIL DAN PEMBAHASAN}

Penelitian ini bertujuan untuk mengetahui pengaruh faktor demografi terhadap literasi keuangan Syariah dan pengaruh literasi keuangan Syariah terhadap perencanaan keuangan dan keputusan investasi. Berikut adalah hasil dari pengolahan data yang menunjukkan tingkat demografi jenis kelamin dan tingkat pendidikan responden penelitian.

Tabel 1. Profil Responden Penelitian (Demografi)

\begin{tabular}{clcc}
\hline No & \multicolumn{1}{c}{ Sosial-Demografi } & Frekuensi & Persentase \\
\hline 1 & Jenis Kelamin & & \\
& Pria & 50 & $33,3 \%$ \\
& Wanita & 100 & $66,7 \%$ \\
2 & Pendidikan Terakhir & & \\
& SMA/SMK/MA & 93 & $62 \%$ \\
& Diploma (D1/D2/D3) & 2 & $1,3 \%$ \\
& Sarjana (S1) & 46 & $30,7 \%$ \\
& Pascasarjana (S2/S3) & 9 & $6 \%$ \\
\hline
\end{tabular}

Berdasarkan tabel 1 maka dapat dilihat responden dalam penelitian ini yang berjenis kelamin pria sebanyak 50 orang $(33,3 \%)$ dan wanita sebanyak 100 orang (66,7\%). Pada faktor demografi kedua yaitu pendidikan terakhir terlihat bahwa responden yang berpendidikan SMA/SMK/MA sebanyak 93 orang (yang saat ini mereka sedang berstatus mahasiswa) atau 62\%. Responden dengan pendidikan terakhir Diploma sebanyak 2 orang atau 1,3\%. Responden dengan tingkat pendidikan terakhir adalah sarjana sebanyak 46 orang atau $(30,7 \%)$ dan pascasarjana sebanyak 9 orang atau $6 \%$.

Data primer dalam penelitian ini diuji menggunakan alat analisis SEM-PLS dimana pada tahap awal terdapat uji outer model dan inner model. Uji outer model dilakukan untuk mengetahui tingkat validitas dan reliabilitas. Instrumen penelitian dikatakan valid jika nilai outer loadings $\geq 0,50$ dan AVE $\geq 0,50$. Berikut adalah hasil uji validitas yang diketahui semua indikator pada variabel penelitian memiliki outer loading $\geq 0,50$ dan AVE $\geq 0,50$. Hal ini menunjukkan bahwa semua indikator valid dalam mengukur variabel yang diukur dan memenuhi syarat validitas konvergen, sehingga dapat digunakan untuk analisis selanjutnya.

Pada tahap selanjutnya dilakukan uji internal consistency. Internal consistency menguji kekonsistenan indikator-indikator dalam mengukur suatu konstruk. Internal consistency dalam PLS dapat menggunakan dua ukuran, yaitu cronbach's alpha dan composite reliability. Rule of thumb cronbach alpha adalah lebih besar dari 0,60, sedangkan rule of thumb composite reliability harus lebih besar dari 
Elvira Maya Adiba. Literasi Keuangan Syariah, Keputusan Investasi, Sosial Demografi

0,70, meskipun nilai 0,60 masih dapat diterima. Berikut adalah hasil perhitungan cronbach alpha dan composite reliability pada pengujian internal consistency.

Tabel 2. Hasil Uji Validitas

\begin{tabular}{|c|c|c|c|c|}
\hline Variabel & $\begin{array}{l}\text { Measurement } \\
\text { Items }\end{array}$ & AVE & $\begin{array}{c}\text { Outer } \\
\text { Loadings }\end{array}$ & Keterangan \\
\hline I & PK.5 & 0,756 & 0,818 & Valid \\
\hline $\begin{array}{c}\text { Perencanaan } \\
\text { Keuangan }\end{array}$ & PK.6 & & 0,918 & Valid \\
\hline II & $\mathrm{KI} .2$ & 0,691 & 0,911 & Valid \\
\hline Keputusan & KI.3 & & 0,743 & Valid \\
\hline Investasi & KI.4 & & 0,831 & Valid \\
\hline
\end{tabular}

Tabel 3. Hasil Uji Reliabilitas

\begin{tabular}{lccc}
\hline \multicolumn{1}{c}{ Variabel } & $\begin{array}{c}\text { Cronbach's } \\
\text { Alpha }\end{array}$ & $\begin{array}{c}\text { Composite } \\
\text { Reliability }\end{array}$ & Keterangan \\
\hline Perencanaan Keuangan & 0,686 & 0,860 & Reliabel \\
Keputusan Investasi & 0,794 & 0,869 & Reliabel \\
\hline
\end{tabular}

Tabel 2 di atas menunjukkan bahwa nilai konsistensi internal dari setiap variabel penelitian memiliki nilai Cronbach's Alpha lebih dari 0,60 dan nilai Composite Reliability lebih dari 0,70. Dengan demikian dapat disimpulkan bahwa masing-masing variabel telah memenuhi reliabilitas yang baik.

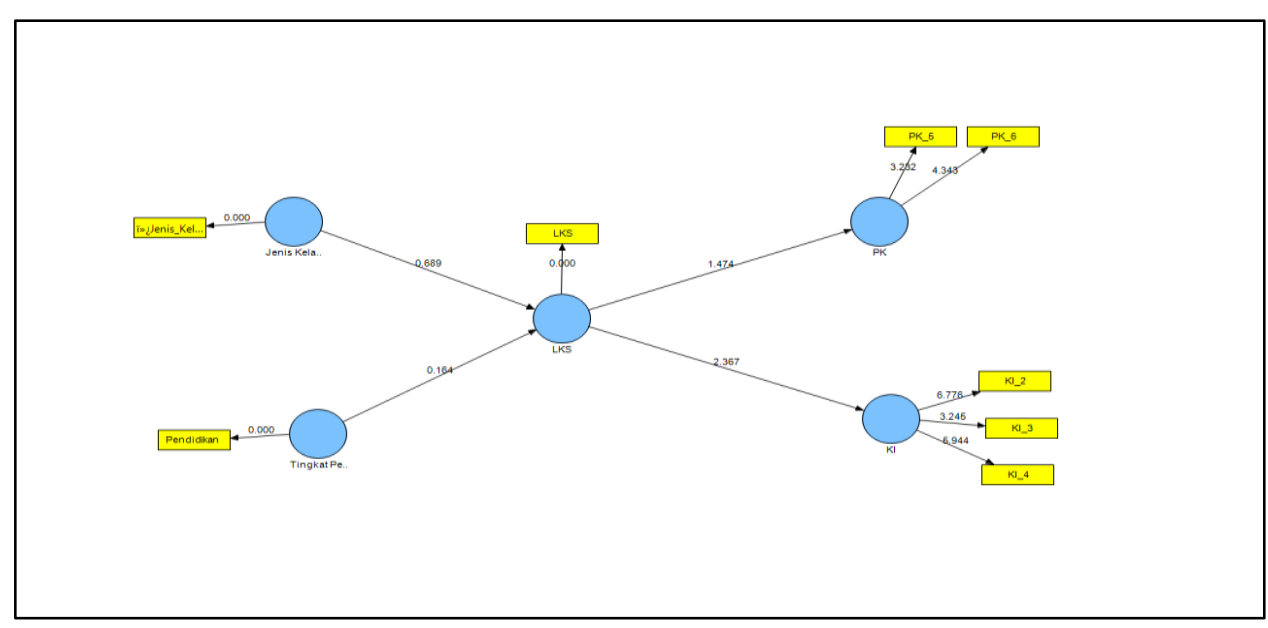

Gambar 2. Hasil Uji Inner Model

Analisis signifikansi faktor yang membentuk travel intention dengan menggunakan analisis PLS dilakukan dengan pengujian 2-tailed. Hipotesis penelitian dapat diterima jika nilai t hitung (t- 
statistic) $\geq 1,96$ atau p-value lebih kecil dari tingkat kesalahan $(\alpha) 5 \%$. Berikut adalah nilai t-hitung (t-statistic) pada inner model PLS.

Tabel 4. Hasil Uji Inner Model

\begin{tabular}{lcc}
\hline \multicolumn{1}{c}{ Variabel } & T-Stat & Keterangan \\
& & \\
\hline Jenis Kelamin $\rightarrow$ LKS & 0,689 & Tidak signifikan \\
Tingkat Pendidikan $\rightarrow$ LKS & 0,164 & Tidak signifikan \\
LKS $\rightarrow$ Perencanaan Keuangan & 1,474 & Tidak signifikan \\
LKS $\rightarrow$ Keputusan Investasi & 2,367 & Signifikan \\
\hline
\end{tabular}

Hasil pengujian dengan menggunakan bootstrapping PLS sesuai tabel diatas dapat dijelaskan sebagai berikut:

1. Nilai t-statictics pengaruh jenis kelamin terhadap literasi keuangan syariah (LKS) sebesar 0,689 atau lebih kecil dari t-tabel $(1,96)$. Hasil tersebut menunjukkan bahwa jenis kelamin tidak berpengaruh signifikan terhadap literasi keuangan syariah.

2. Nilai $t$-statictics pengaruh tingkat pendidikan terhadap literasi keuangan syariah (LKS) sebesar 0,164 atau lebih kecil dari t-tabel (1,96). Hasil tersebut menunjukkan bahwa tingkat pendidikan tidak berpengaruh signifikan terhadap literasi keuangan syariah.

3. Nilai t-statictics pengaruh literasi keuangan syariah terhadap perencanaan keuangan sebesar 1,474 atau lebih kecil dari t-tabel $(1,96)$. Hasil tersebut menunjukkan bahwa literasi keuangan syariah tidak berpengaruh signifikan terhadap perencanaan keuangan.

4. Nilai t-statictics pengaruh literasi keuangan syariah terhadap perencanaan keuangan sebesar 2,367 atau lebih besar dari t-tabel (1,96). Hasil tersebut menunjukkan bahwa literasi keuangan syariah berpengaruh signifikan terhadap keputusan investasi.

Hasil penelitian ini menunjukkan bahwa variabel jenis kelamin dan tingkat pendidikan tidak berpengaruh signifikan terhadap literasi keuangan syariah. Hasil ini berbeda dengan penelitian sebelumnya yang dilakukan oleh Hassan Al-Tamimi \& Anood Bin Kalli (Hassan Al-Tamimi \& Anood Bin Kalli, 2009) dan Abdullah, AbWahab, Sabar, \& Abu (2017). Responden penelitian ini didominasi oleh responden wanita. Menurut Chen \& Volpe (1998) dalam Puspita et al. (2021) bahwa tingkat literasi keuangan mahasiswa laki-laki lebih baik daripada wanita karena wanita kurang tertarik dengan topik keuangan. Hal ini juga diperkuat dengan penjelasan dari Ningtyas (2019) bahwa wanita cenderung memiliki tingkat literasi keuangan rendah.

Tingkat pendidikan terakhir juga tidak berpengaruh signifikan terhadap literasi keuangan syariah. Hal ini berbeda dengan hasil penelitian sebelumnya yang dilakukan oleh Hassan Al-Tamimi 
Elvira Maya Adiba. Literasi Keuangan Syariah, Keputusan Investasi, Sosial Demografi

\& Anood Bin Kalli (Hassan Al-Tamimi \& Anood Bin Kalli, 2009) dan Abdullah, AbWahab, Sabar, \& Abu (Abdullah et al., 2017). Ningtyas (Ningtyas, 2019) juga menjelaskan bahwa masyarakat yang berpenghasilan rendah memiliki literasi keuangan yang rendah pula. Responden pada penilitian ini didominasi oleh respoden dengan tingkat pendidikan SMA/SMK/MA yang saat ini masih berstatus mahasiswa. Kelompok responden tersebut mayoritas belum memiliki pendapatan sendiri atau masih ada pihak lain sebagai penyokong keuangan.

Literasi keuangan syariah tidak berpengaruh signifikan terhadap perencanaan keuangan. Hal ini berbeda dengan hasil penelitian Ningtyas (Ningtyas, 2019) dan Setyowati et. al. (Setyowati et al., 2018). Berdasarkan hasil uji literasi keuangan syariah, nilai rata-rata hasil ujinya adalah 79 dimana nilai tersebut masuk dalam kategori well literate. Semakin baik tingkat literasi keuangan syariah, maka seharusnya semakin baik perencanaan keuangannya. Hal tersebut berbeda pada penelitian ini dikarenakan responden dalam penelitian ini didominasi oleh responden dengan tingkat pendidikan terakhir adalah SMA/SMK/MA yang belum memiliki perencanaan keuangan yang baik, karena masih berstatus mahasiswa.

Literasi keuangan syariah berpengaruh signifikan terhadap keputusan investasi. Hal ini sejalan dengan hasil penelitian yang dilakukan oleh Janor et al. (2016) dan Hassan Al-Tamimi \& Anood Bin Kalli (Hassan Al-Tamimi \& Anood Bin Kalli, 2009). Abdeldayem (Abdeldayem, 2016) menjelaskan bahwa kelompok responden dengan tingkat literasi yang tinggi lebih memilih berinvestasi pada produk keuangan yang lebih berisiko dan return yang tinggi seperti asuransi jiwa, reksa dana, saham, obligasi, dana pensiun, kartu kredit, mortgage, dan valas. Hal ini berbalik dengan kelompok dengan literasi keuangan rendah yang lebih memilih berinvestasi pada produk keuangan yang lebih aman seperti tabungan dan deposito. Sejalan dengan hasil penelitian ini bahwa responden memiliki produk investasi pada keuangan syariah didominasi oleh produk tabungan rencana.

\section{SIMPULAN}

Hasil dari penelitian ini yaitu faktor demografi dan tingkat pendidikan tidak berpengaruh terhadap literasi keuangan syariah. Literasi keuangan Syariah juga tidak berpengaruh terhadap perencanaan keuangan. Hasil lainnya adalah literasi keuangan Syariah berpengaruh signifikan terhadap keputusan investasi. Penelitian ini memiliki keterbatasan, sehingga penelitian selanjutnya perlu dilakukan seperti mendiferensiasikan faktor demografi antar generasi (generasi X, Y, dan Z). Hasil penelitian diharapkan mampu memberikan masukan kepada stakeholder terkait untuk meningkatkan market share keuangan Syariah di Indonesia.

\section{REFERENSI}


Abdeldayem, M. M. (2016). Is There a Relationship Between Financial Literacy and Investment Decisions in the Kingdom of Bahrain? Management and Administrative Sciences Review, 5(4), 203 221.

Abdullah, M. A., AbWahab, S. N. A., Sabar, S., \& Abu, F. (2017). Factors determining Islamic financial literacy among undergraduates. Journal of Emerging Economies \& Islamic Research, 5(2), 67-76.

Alamsyah, H. (2012). Perkembangan dan Prospek Perbankan Syariah Indonesia: Tantangan Dalam Menyongsong MEA 2015. Milad Ke-8 Ikatan Abli Ekonomi Islam (LAEI), April 2012,1-8.

Anshori, M., \& Iswati, S. (2009). Buku Ajar Metodologi Penelitian Kuantitatif. Pusat Penerbitan dan Percetakan Unair.

Antara, P. M., Musa, R., \& Hassan, F. (2016). Bridging Islamic Financial Literacy and Halal Literacy: The Way Forward in Halal Ecosystem. Procedia Economics and Finance, 37(16), 196202. https://doi.org/10.1016/S2212-5671(16)30113-7

Boon, T. H., Yee, H. S., \& Ting, H. W. (2011). Financial Literacy and Personal Financial Planning in Klang Valley, Malaysia. 5(1), 149-168.

Hair, J. et al. (2017). A Primer on Partial Least Square Structural Equation Model (PLS-SEM). SAGE Publications, Inc. California. USA.

Hassan Al-Tamimi, H. A., \& Anood Bin Kalli, A. (2009). Financial literacy and investment decisions of UAE investors. Journal of Risk Finance, 10(5), 500-516. https://doi.org/10.1108/15265940911001402

Hidajat, T., \& Hamdani, M. (2017). Measuring Islamic financial literacy. Advanced Science Letters, 23(8), 7173-7176. https://doi.org/10.1166/asl.2017.9321

Janor, H., Yakob, R., Azuan Hashim, N., \& Aniza Che Wel, C. (2016). Financial literacy and investment decisions in Malaysia and United Kingdom: A comparative analysis. Malaysian Journal of Society and Space, 12(2), 106-118.

Ningtyas, M. N. (2019). Literasi Keuangan pada Generasi Milenial. Jurnal Ilmiah Bisnis Dan Ekonomi Asia, 13(1), 20-27. https://doi.org/10.32812/jibeka.v13i1.111

Otoritas Jasa Keuangan. (2016). Survei Nasional Literasi dan Inklusi Keuangan 2016. Survey Report, $1-26$.

Otoritas Jasa Keuangan. (2017). Strategi Nasional Literasi Keuangan Indonesia. Otoritas Jasa Keuangan, 1-99.

Puspita, A. T., Lubis, D., \& Muthohharoh, M. (2021). Faktor - Faktor yang Memengarubi Tingkat Literasi Kenangan Syariah pada Mahasiswa Muslim di Bogor Determinants of Islamic Financial Literacy Level of Muslim Students in Bogor. 9(1), 1-20. https://doi.org/10.29244/jam.9.1.1-20 
Elvira Maya Adiba. Literasi Keuangan Syariah, Keputusan Investasi, Sosial Demografi

Setyawati, I., \& Suroso, S. (2016). Sharia Financial Literacy And Effect On Social Economic Factors (Survey On Lecturer In Indonesia). International Journal of Scientific \& Technology Research, 5(02), 92-102.

Setyowati, A., Harmadi, H., \& Sunarjanto, S. (2018). Islamic Financial Literacy and Personal Financial Planning: A Socio-Demographic Study. 22(1), 63-72.

Sholikah, B. (2017). Melonjak, Pangsa Pasar Keuangan Syariah Capai 8 Persen. https://republika.co.id/berita/ekonomi/syariah-ekonomi/17/10/27/oyhc0f415-melonjakpangsa-pasar-keuangan-syariah-capai-8-persen 